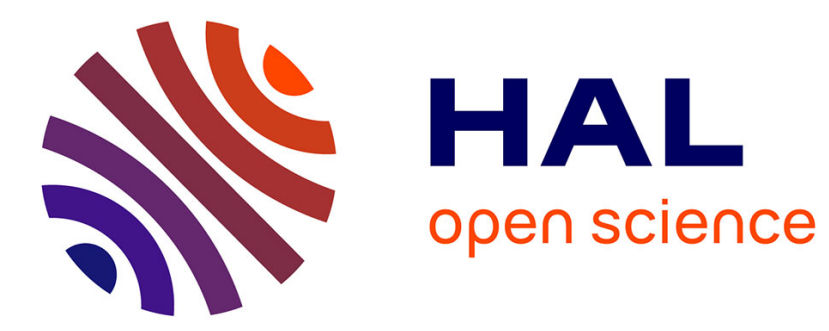

\title{
The U4Re7Si6 type - Trends in electronic structure and chemical bonding
}

Samir F. Matar, Bernard Chevalier, Rainer Pöttgen

\section{To cite this version:}

Samir F. Matar, Bernard Chevalier, Rainer Pöttgen. The U4Re7Si6 type - Trends in electronic structure and chemical bonding. Solid State Sciences, 2014, 27, pp.5-10. 10.1016/j.solidstatesciences.2013.10.008 . hal-00906699

\section{HAL Id: hal-00906699 \\ https://hal.science/hal-00906699}

Submitted on 20 Nov 2013

HAL is a multi-disciplinary open access archive for the deposit and dissemination of scientific research documents, whether they are published or not. The documents may come from teaching and research institutions in France or abroad, or from public or private research centers.
L'archive ouverte pluridisciplinaire HAL, est destinée au dépôt et à la diffusion de documents scientifiques de niveau recherche, publiés ou non, émanant des établissements d'enseignement et de recherche français ou étrangers, des laboratoires publics ou privés. 


\title{
The $\mathrm{U}_{4} \mathrm{Re}_{7} \mathrm{Si}_{6}$ type - Trends in electronic structure and chemical bonding
}

\author{
Samir F. Matar ${ }^{a,}$, Bernard Chevalier ${ }^{\mathrm{a}}$, Rainer Pöttgen ${ }^{\mathrm{b}}$ \\ a CNRS, Université de Bordeaux, ICMCB, 87 Avenue Dr. A. Schweitzer, F-33608 \\ Pessac-Cedex, France \\ $b \quad$ Institut für Anorganische und Analytische Chemie, Universität Münster, \\ Corrensstrasse 30, D-48149 Münster, Germany
}

Keywords:

$\mathrm{U}_{4} \mathrm{Re}_{7} \mathrm{Si}_{6}$-type structure

Electronic structure

Trends in chemical bonding

\section{A B S T R A C T}

The electronic structures and chemical bonding of selected ternary compounds of the family of $\mathrm{A}_{4} \mathrm{~T}_{7} \mathrm{X}_{6}$ (of $\mathrm{U}_{4} \mathrm{Re}_{7} \mathrm{Si}_{6}$-type) intermetallics have been studied by ab initio methods. The calculations for two series: $\mathrm{Mg}_{4} \mathrm{Rh}_{7} \mathrm{P}_{6}, \mathrm{Sc}_{4} \mathrm{Co}_{7} \mathrm{Ge}_{6}, \mathrm{Ti}_{4} \mathrm{Co}_{7} \mathrm{Ge}_{6}$ and uranium containing $\mathrm{U}_{4} \mathrm{Re}_{7} \mathrm{Si}_{6}, \mathrm{U}_{4} \mathrm{Ru}_{7} \mathrm{Ge}_{6}$, and $\mathrm{U}_{4} \mathrm{Ru}_{7} \mathrm{As}_{6}$ show common bonding characteristics pertaining to main $\mathrm{T} 1-\mathrm{X}$ and $\mathrm{T} 2-\mathrm{X}$ interaction $(\mathrm{T}=$ transition metal and $\mathrm{X}=\mathrm{p}$-element) due to the peculiar crystal chemistry with $\mathrm{T} 1 @ \mathrm{X}_{6}$ and $\mathrm{T} 2 @ \mathrm{X}_{4}$ coordination polyhedra. The uranium compounds are found to be stabilized in a spin polarized ferromagnetic configuration, especially for $\mathrm{U}_{4} \mathrm{Ru}_{7} \mathrm{Ge}_{6}$ (in agreement with experiment) and $\mathrm{U}_{4} \mathrm{Ru}_{7} \mathrm{As}_{6}$.

(c) 2013 Elsevier. All rights reserved.

\section{Introduction}

The cubic $\mathrm{U}_{4} \mathrm{Re}_{7} \mathrm{Si}_{6}$ structure was determined more than 30 years ago [1]. It crystallizes with space group $\operatorname{Im} \overline{3} m$, Pearson symbol cI34 with one uranium $(8 c)$, two 
rhenium (12d and $2 a$ ), and one silicon (12e) sites. The unit cell is presented in Fig. 1. The $\mathrm{U}_{4} \mathrm{Re}_{7} \mathrm{Si}_{6}$ structure can easily be described by a condensation of two central building units, i.e. Re1@ $\mathrm{Si}_{6}$ octahedra and slightly distorted $\mathrm{U} @ \operatorname{Re}{ }_{6} \mathrm{Si}_{6}$ cuboctahedra. These two basic building units are packed in a $b c c$ fashion. Each $\mathrm{Re} 1 @ \mathrm{Si}_{6}$ octahedron is coordinated by eight $\mathrm{U} @ \operatorname{Re} 2{ }_{6} \mathrm{Si}_{6}$ cuboctahedra.

$\mathrm{U}_{4} \mathrm{Re}_{7} \mathrm{Si}_{6}$ is the prototype for more than 70 intermetallics [2]. The $\mathrm{U}_{4} \mathrm{Re}_{7} \mathrm{Si}_{6}$-type structure has certain flexibility for substitution (elements of different size) and changes in the valence electron concentration. Uranium can be substituted by magnesium, titanium, zirconium, hafnium, and the rare earth elements. On the transition metal site compounds with $\mathrm{Tc}, \mathrm{Re}, \mathrm{Co}, \mathrm{Rh}, \mathrm{Ir}, \mathrm{Ru}$, and Os have been reported. Most ternary phases are germanides, but also few silicides, phosphides, and arsenides are formed. These different element combinations lead to drastic changes in the lattice parameter. The extreme values are $a=767.3$ pm for $\mathrm{Ti}_{4} \mathrm{Co}_{7} \mathrm{Ge}_{6}[3]$ vs. $a=875.7 \mathrm{pm}$ for $\mathrm{Gd}_{4} \mathrm{Rh}_{7} \mathrm{Sb}_{6}$ [4].

The rare earth and uranium containing representatives have been studied with respect to their magnetic properties. Interesting examples are the intermediate-valent ytterbium compounds $\mathrm{Yb}_{4} \mathrm{Ru}_{7} \mathrm{Sb}_{6}$ [4] and $\mathrm{Yb}_{4} \mathrm{Rh}_{7} \mathrm{Sb}_{6}$ [5]. The isotypic germanides $\mathrm{Yb}_{4} \mathrm{Rh}_{7} \mathrm{Ge}_{6}$ [6-8] and $\mathrm{Yb}_{4} \mathrm{Ir}_{7} \mathrm{Ge}_{6}$ [8] contain stable trivalent ytterbium and lowtemperature measurements point to antiferromagnetic ordering of the ytterbium magnetic moments at $0.49 \mathrm{~K}$ [6]. Among the uranium compounds $\mathrm{U}_{4} \mathrm{Tc}_{7} \mathrm{Si}_{6}$ orders antiferromagnetically at $25 \mathrm{~K}[9]$ and $\mathrm{U}_{4} \mathrm{Ru}_{7} \mathrm{Ge}_{6}$ is a $6.8 \mathrm{~K}$ ferromagnet $[10,11]$. The solid solution $\mathrm{Mn}_{4}\left(\mathrm{Ir}_{7-\mathrm{x}} \mathrm{Mn}_{\mathrm{x}}\right) \mathrm{Ge}_{6}$ shows composition-dependent magnetic behaviour. The $\mathrm{x}=0$ phase shows long-range antiferromagnetic ordering at $228 \mathrm{~K}$ but a cluster glass behaviour is observed for $\mathrm{x}=1.3$ [12].

Although many of the $\mathrm{U}_{4} \mathrm{Re}_{7} \mathrm{Si}_{6}$ type phases have structurally been characterized on the basis of single crystal diffractometer data, to the best of our knowledge, none of them has been studied with respect to its electronic structure and chemical bonding. For the present study we have selected the structures $\mathrm{Mg}_{4} \mathrm{Rh}_{7} \mathrm{P}_{6}$ [13], $\mathrm{Sc}_{4} \mathrm{Co}_{7} \mathrm{Ge}_{6}$ [14], and $\mathrm{Ti}_{4} \mathrm{Co}_{7} \mathrm{Ge}_{6}$ [3] where none of the elements carries a permanent magnetic moment. A second part of the work deals with the uranium compounds $\mathrm{U}_{4} \mathrm{Re}_{7} \mathrm{Si}_{6}[1], \mathrm{U}_{4} \mathrm{Ru}_{7} \mathrm{Ge}_{6}[10$, 11], and $\mathrm{U}_{4} \mathrm{Ru}_{7} \mathrm{As}_{6}[15]$. The six structures were studied by DFT based calculations [16, 
17], focusing on the density of states, magnetic ground states as well as trends in atomic charges and overlap populations.

\section{Computational methodology}

Two computational methods within the DFT were used in a complementary manner. The Vienna ab initio simulation package (VASP) code [18, 19] allows geometry optimization and total energy calculations. For this we use the projector augmented wave (PAW) method $[19,20]$, built within the generalized gradient approximation (GGA) scheme following Perdew, Burke and Ernzerhof (PBE) [21]. Also preliminary calculations with local density approximation (LDA) [22] led to underestimated volumes versus experiment. The conjugate-gradient algorithm [23] is used in this computational scheme to relax the atoms. The tetrahedron method with Blöchl corrections [20] as well as a Methfessel-Paxton [24] scheme were applied for both geometry relaxation and total energy calculations. Brillouin-zone (BZ) integrals were approximated using special k-point sampling. The optimization of the structural parameters was performed until the forces on the atoms were less than $0.02 \mathrm{eV} / \AA$ and all stress components less than $0.003 \mathrm{eV} / \AA^{3}$. The calculations are converged at an energy cut-off of $400 \mathrm{eV}$ for the plane-wave basis set with respect to the k-point integration with a starting mesh of $4 \times 4 \times 4$ up to $8 \times 8 \times 8$ for best convergence and relaxation to zero strains. The calculations are scalar relativistic.

Then all-electron calculations within the GGA were carried out for a full description of the electronic structure and the properties of chemical bonding, using the full potential scalar-relativistic augmented spherical wave (ASW) method [25, 26]. In the minimal ASW basis set, we chose the outermost shells to represent the valence states and the matrix elements were constructed using partial waves up to $l_{\max }+1=4$ for $\mathrm{U}$, $l_{\max }+1=3$ for $\mathrm{Ru}, \mathrm{Rh}$ or $\mathrm{Re}$ and $l_{\max }+1=2$ for $\mathrm{P}, \mathrm{Ge}$, Si or As. Self-consistency was achieved when charge transfers and energy changes between two successive cycles were below $10^{-8}$ and $10^{-6} \mathrm{eV}$, respectively. BZ integrations were performed using the linear tetrahedron method within the irreducible wedge. In order to optimize the basis set, additional augmented spherical waves are placed at carefully selected interstitial sites (IS). Besides the site projected density of states, we discuss qualitatively the pair interactions based on the overlap population analysis with the crystal orbital overlap 
population (COOP) [27]. In the plots, positive, negative, and zero COOP indicate bonding, anti-bonding, and non-bonding interactions, respectively.

\section{Results and discussion}

\subsection{Crystal chemical considerations}

Before starting the theoretical description we draw back to the crystal chemical details of the $\mathrm{U}_{4} \mathrm{Re}_{7} \mathrm{Si}_{6}$ type phases, starting with the prototype. The four crystallographically independent sites are as follows: $U$ on $8 c(1 / 41 / 41 / 4), \operatorname{Re} 1$ on $12 d(1 / 4$ $\left.0 \begin{array}{l}1 / 2\end{array}\right), \operatorname{Re} 2$ on $2 a\left(\begin{array}{lll}0 & 0 & 0\end{array}\right)$, and $\mathrm{Si}$ on $12 e\left(\begin{array}{lll}x & 0 & 0\end{array}\right)$ with $x=0.29$. Thus one has structural flexibility by variation of the cubic lattice parameter and the $x$ parameter of the $12 e$ silicon site.

For comparison of the different phases we start with the striking coordination polyhedra (Fig. 2) for a general $A_{4} T_{7} X_{6}$ compound. The $T 1$ and $T 2$ atoms have octahedral and distorted tetrahedral $X$ coordination, respectively. In agreement with the change in coordination number one always observes the shorter $T-X$ distances for the tetrahedra. The shorter $T 1-X$ distances are all close to the sums of the covalent radii [28]. This leads to significant $T-X$ bonding, which is addressed in the following paragraphs. Always four $T 2 X_{4}$ tetrahedra are condensed via a common edge and one observes trans-edge-sharing with the neighboring tetrameric units. The $T 1 X_{6}$ octahedra share all corners with the $T 2 X_{4}$ tetrahedra. Each $A$ atom has distorted cuboctahedral $T 2{ }_{6} X_{6}$ coordination with shorter $A-T 2$ vs $A-X$ distances in all cases.

The electronic flexibility of the $\mathrm{U}_{4} \mathrm{Re}_{7} \mathrm{Si}_{6}$ type is expressed by the valence electron count which ranges from 92 for $\mathrm{Lu}_{4} \mathrm{Ru}_{7} \mathrm{Ge}_{6}$ [29] to 105 for $\mathrm{Lu}_{4} \mathrm{Rh}_{7} \mathrm{Sb}_{6}$ [4]. Besides this formal counting of valence electrons also the electronegativity differences in a given $A_{4} T_{7} X_{6}$ compound play an important role with respect to the bonding situation. These charge trends are first considered in the following section on chemical bonding and electronic structure followed by a deeper study of three uranium containing compounds, also with respect to their magnetic ground state.

\subsection{Geometry optimization and charge analysis.}

Table 1 provides in two sub-tables the experimental and calculated crystal structure parameters for the non magnetic representatives $\mathrm{Mg}_{4} \mathrm{Rh}_{7} \mathrm{P}_{6}, \mathrm{Sc}_{4} \mathrm{Co}_{7} \mathrm{Ge}_{6}$, and $\mathrm{Ti}_{4} \mathrm{Co}_{7} \mathrm{Ge}_{6}$ 
and the uranium magnetic series: $\mathrm{U}_{4} \mathrm{Re}_{7} \mathrm{Si}_{6}, \mathrm{U}_{4} \mathrm{Ru}_{7} \mathrm{Ge}_{6}$, and $\mathrm{U}_{4} \mathrm{Ru}_{7} \mathrm{As}_{6}$. The symmetry and the I centering are kept throughout the cycles of full geometry relaxations resulting into a good agreement for the $a$ lattice parameter with experiment. Note that the $x$ value determining the position of the $p$ element $(\mathrm{X})$ and defining the 'flexibility' of the structure converges to a calculated value slightly larger than in the experiments.

Nevertheless the obtained geometries allow to draw trends in charge changes. This is achieved through the analysis of the charge density issued from the self consistent calculations using the AIM (atoms in molecules theory) approach [30] developed by Bader who devised an intuitive way of splitting molecules into atoms as based purely on the electronic charge density. Typically in chemical systems, the charge density reaches a minimum between atoms and this is a natural region to separate them from each other. Such an analysis does not constitute a tool for evaluating absolute ionizations. The results of computed charge changes $(\Delta \mathrm{Q})$ in $e$ units are such that they lead to neutrality when the respective multiplicities are accounted for. They are presented in Table 1. Also for the sake of completeness the Pauling electronegativites are provided for each constituent.

In Table 1a), the $A$ cations are all ionized to closely +2 charge in spite of their different character, formally divalent, trivalent and tetravalent for $\mathrm{Mg}, \mathrm{Sc}$ and $\mathrm{Ti}$ respectively. This is more directly related with the increasing electronegativities whereby less electrons are released toward the $T$ and $X$ sites where larger changes occur. Here interplay between $T$ and $X$ coordination, namely tetrahedra and octahedra with $X$ of $T 1$ and $T 2$ respectively, as well as the electronegativities are the leading effects. In $\mathrm{Mg}_{4} \mathrm{Rh}_{7} \mathrm{P}_{6}$, there is hardly any charge on $\mathrm{Rh} 1$ whereas most electrons are transferred to phosphorus and $\mathrm{Rh} 2$. The changes between $\mathrm{Sc}_{4} \mathrm{Co}_{7} \mathrm{Ge}_{6}$, and $\mathrm{Ti}_{4} \mathrm{Co}_{7} \mathrm{Ge}_{6}$ are smaller and more electrons are found on cobalt versus $\mathrm{Ge}$ due to the larger electronegativity of $\mathrm{Ti}$ versus Sc.

Turning to the uranium family there is an increasingly positively ionized uranium along the series with the electrons transferred to $T$ and $X$. Larger negative charges characterize the $T 2$ site versus $T 1$ due to coordination effects with $X$ and the largest effects are observed for $\mathrm{U}_{4} \mathrm{Ru}_{7} \mathrm{As}_{6}$ which shows an overall larger ionization with respect to $\mathrm{U}_{4} \mathrm{Ru}_{7} \mathrm{Ge}_{6}$, As being the most electronegative among the $X p$-elements here. 


\subsection{Electronic density of states and chemical bonding}

Calculations used the experimental parameters with the full potential scalar relativistic ASW method which also implements the chemical bonding qualitative descriptions [26]. Firstly spin degenerate (non spin polarized NSP) calculations with total spins are done. At self consistent convergence the charge transfer follows the trends observed above with additional charge residues (corresponding to less than 0.15 electrons) from the atomic spheres to IS. Then spin polarized SP calculations are carried out.

\section{3.a. The non-magnetic representatives $\mathrm{Mg}_{4} \mathrm{Rh}_{7} \mathrm{P}_{6}, \mathrm{Sc}_{4} \mathrm{Co}_{7} \mathrm{Ge}_{6}$, and $\mathrm{Ti}_{4} \mathrm{Co}_{7} \mathrm{Ge}_{6}$}

The site projected density of states PDOS are shown in Fig. 3. The energy reference along the $\mathrm{x}$-axis is with respect to the Fermi level, $\mathrm{E}_{\mathrm{F}}$. Finite PDOS arising from all species are found at $\mathrm{E}_{\mathrm{F}}$ signaling a metallic behavior with however a major difference of small DOS of dispersed, itinerant states, for $\mathrm{Mg}_{4} \mathrm{Rh}_{7} \mathrm{P}_{6}$ whereas $\mathrm{Sc}_{4} \mathrm{Co}_{7} \mathrm{Ge}_{6}$ and $\mathrm{Ti}_{4} \mathrm{Co}_{7} \mathrm{Ge}_{6}$ exhibit larger DOS at $\mathrm{E}_{\mathrm{F}}$ with dominant cobalt $d$-character. This arises from the nature of the transition element, namely $4 d(\mathrm{Rh})$ and $3 d(\mathrm{Co})$ characterized by broad and narrow $d$ bands respectively. The consequence of a larger $d$-PDOS at $\mathrm{E}_{\mathrm{F}}$ is a possible tendency to magnetic instability in such non magnetic NSP configuration, especially in $\mathrm{Ti}_{4} \mathrm{Co}_{7} \mathrm{Ge}_{6}$ which exhibits the largest DOS at $\mathrm{E}_{\mathrm{F}}$. However no magnetic moments could be found from subsequent spin-polarized (SP) calculations. The similar PDOS lines below $\mathrm{E}_{\mathrm{F}}$, i.e. within the valence band (VB), signal the quantum mixing between the different constituents leading to the chemical bonding. This is illustrated in Fig. 4 with the COOP using the overlap integrals of the valence states. The plots use one atom of each kind in order to establish trends of bonding strengths. The largest bonding is for Rh-P and Co-Ge with larger Co1-Ge relatively to Co2-Ge as it could be expected from the coordination polyhedra of $T 1 @ X_{6}$ versus $T 2 @ X_{4}$ (Fig. 2). However dominant Rh2-P versus Rh1-P is obtained. This follows the charge transfer with is negligible on Rh1 (Table 1a).

\section{3.b. The magnetic representatives $U_{4} R e_{7} S i_{6}, U_{4} R u_{7} G e_{6}$, and $U_{4} R u_{7} A s_{6}$}

Fig. 5 shows the NSP PDOS. Whereas similar VB features of quantum mixing similar to the above studied series, i.e. strongest bonding for $T-X$ versus $\mathrm{U}-T$ and $\mathrm{U}-X$ following bond lengths, ex. $\mathrm{d}(\mathrm{Ru} 1-\mathrm{As})=2.56 \AA \mathrm{d}, \mathrm{d}(\mathrm{Ru} 2-\mathrm{As}) \sim 2.64 \AA$ and $\mathrm{d}(\mathrm{U}-\mathrm{Ru} 2) \sim$ 
$2.95 \AA$, there is a relevant trend of increasing PDOS@ $\mathrm{E}_{\mathrm{F}}$ along the series due to uranium $5 f$ states. In spite of their rather localized nature, $\mathrm{U}(5 f)$ states are particular in the actinide series and uranium acts in many intermetallics as a transition metal [31]. Then the Stoner mean field theory of band ferromagnetism can be applied to address the magnetic instability [32]. This is summarized as follows: the total energy of the spin system results from the exchange and kinetic energies. Referring the total energy to the non-magnetic state (NSP), this is expressed as $\mathrm{E}=$ constant $\left\{1-\mathrm{I} n\left(\mathrm{E}_{\mathrm{F}}\right)\right\}$. In this expression, $\mathrm{I}(\mathrm{eV})$ is the Stoner integral and $n\left(\mathrm{E}_{\mathrm{F}}\right)(1 / \mathrm{eV})$ is the PDOS value for a given state -here $5 f$ - at the Fermi level in the non-magnetic state (Fig. 5). If the unit-less Stoner product $\mathrm{I} n\left(\mathrm{E}_{\mathrm{F}}\right)$ is larger than 1, energy is lowered and the system stabilizes in a magnetically ordered configuration. Then the product $\mathrm{I} n\left(\mathrm{E}_{\mathrm{F}}\right)$ provides a criterion for the stability of the spin system. From quantum theoretical calculations [31] the value of $\mathrm{I}\{\mathrm{U}(5 f)\}=0.51 \mathrm{eV}$ was derived. The $n\left(\mathrm{E}_{\mathrm{F}}\right)\{\mathrm{U}(5 f)\}$ values from NSP calculations for $\mathrm{U}_{4} \mathrm{Re}_{7} \mathrm{Si}_{6}, \mathrm{U}_{4} \mathrm{Ru}_{7} \mathrm{Ge}_{6}$, and $\mathrm{U}_{4} \mathrm{Ru}_{7} \mathrm{As}_{6}$ are 2.0, 3.8 and 6.6 respectively. The corresponding Stoner products are then 1.02, 1.98 and 2.37 with Stoner criterion $1-\mathrm{I} n\left(\mathrm{E}_{\mathrm{F}}\right)$ of -0.02 for $\mathrm{U}_{4} \mathrm{Re}_{7} \mathrm{Si}_{6},-0.98$ for $\mathrm{U}_{4} \mathrm{Ru}_{7} \mathrm{Ge}_{6}$ and -1.37 for $\mathrm{U}_{4} \mathrm{Ru}_{7} \mathrm{As}_{6}$. These negative values should lead to energy lowering upon the onset of magnetization. However one can notice that the close to zero magnitude for the Re compound puts it on the verge of magnetic instability contrary to the $\mathrm{Ru}$ members, especially for $\mathrm{U}_{4} \mathrm{Ru}_{7} \mathrm{As}_{6}$ which is predicted to have the largest magnitude of magnetic moment.

Spin polarized (SP) calculations actually lead to no spin polarization in the $\mathrm{Re}$ compound whereas the Ru compounds show finite magnetic polarizations as follows:

$$
\begin{aligned}
& \mathrm{U}_{4} \mathrm{Ru}_{7} \mathrm{Ge}_{6}: \mathrm{M}(\mathrm{U})=0.58 \mu_{\mathrm{B}}, \mathrm{M}(\mathrm{Ru} 1 / \mathrm{Ru} 2)=0.05 / 0.08 \mu_{\mathrm{B}}, \mathrm{M}(\mathrm{Ge})=0.003 \mu_{\mathrm{B}}, \\
& \mathrm{U}_{4} \mathrm{Ru}_{7} \mathrm{As}_{6}: \mathrm{M}(\mathrm{U})=1.18 \mu_{\mathrm{B}}, \mathrm{M}(\mathrm{Ru} 1 / \mathrm{Ru} 2)=0.09 / 0.10 \mu_{\mathrm{B}}, \mathrm{M}(\mathrm{As})=0.002 \mu_{\mathrm{B}} .
\end{aligned}
$$

The results for $\mathrm{U}_{4} \mathrm{Ru}_{7} \mathrm{Ge}_{6}$ are in agreement with the experimentally evidenced ferromagnetic ground state $[10,11]$. The largest polarization is carried by uranium and much less by the transition metal at both sites due to the quantum mixing with uranium itinerant states; negligible polarization is observed on the $p$-element. Concomitantly the energy is respectively lowered by $2.1 \mathrm{eV}$ and $2.8 \mathrm{eV}$ per formula unit with respect to NSP configuration, in agreement with the Stoner theory [32]. 
These results are mirrored by the site and spin projected PDOS for the three compounds given in Fig. 6. There is no energy shift between the two spin DOS ( $\uparrow$ and $\downarrow$ ) in the Re compound (top) whereas finite energy shift mainly affecting uranium PDOS is observed in the two Ru compounds (middle and bottom).

Note that the spin only values obtained from scalar relativistic calculations should be corrected by the spin orbit coupling (SOC), i.e. with the orbital moment which amounts to 2.7 in uranium [31]. This obeys Hund's $3^{\text {rd }}$ rule whereby the actual quantum number is $\mathbf{J}$ with $\mathbf{J}=|\mathrm{L}-\mathrm{S}|$ for less than half filled $5 f$ subshell and $\mathbf{J}=|\mathrm{L}+\mathrm{S}|$ for more than half filled subshell.

\section{Acknowledgments}

This work was financially supported by the Deutsche Forschungsgemeinschaft. We acknowledge support from the Conseil Régional d'Aquitaine. Computational facilities were provided by MCIA-Université de Bordeaux clusters. 


\section{References}

[1] L.G. Akselrud, Ya.P. Yarmolyuk, E.I. Gladyshevskii, Dopov. Akad Nauk Ukr. RSR, Ser. A (1978) 359.

[2] P. Villars, K. Cenzual, Pearson's Crystal Data: Crystal Structure Database for Inorganic Compounds (release 2012/13), ASM International ${ }^{\circledR}$, Materials Park, Ohio, 2012.

[3] R.R. Olenych, Y.P. Yarmolyuk, R.V. Skokozdne, Ukr. Fiz. Zh. Russ. Ed. 32 (1987) 615.

[4] I. Schellenberg, U.Ch. Rodewald, C. Schwickert, M. Eul, R. Pöttgen, Z. Naturforsch. 68b (2013) 971.

[5] I. Schellenberg, M. Eul, R. Pöttgen, Z. Kristallogr. 225 (2010) 339.

[6] J. Ferstl, F. Weickert, C. Geibel, J. Magn. Magn. Mater. 272-276 (2004) e71.

[7] K. Katoh, H. Abe, D. Negishi, G. Terui, Y. Niide, A. Ochiai, J. Magn. Magn. Mater. 279 (2004) 118.

[8] B. Heying, K. Katoh, Y. Niide, A. Ochiai, R. Pöttgen, Z. Anorg. Allg. Chem. 630 (2004) 1423.

[9] F. Wastin, J. Rebizant, J.P. Sanchez, A. Blaise, J. Goffart, J.C. Spirlet, C.T. Walker, J. Fuger, J. Alloys Compd. 210 (1994) 83.

[10] B. Lloret, B. Buffat, B. Chevalier, J. Etourneau, J. Magn. Magn. Mater. 67 (1987) 232.

[11] S.A.M. Mentink, G.J. Nieuwenhuys, A.A. Menovsky, J.A. Mydosh, J. Appl. Phys. 69 (1991) 5484.

[12] T. Eriksson, P. Nordblad, Y. Andersson, J. Solid State Chem. 178 (2005) 1495.

[13] A. Wurth, A. Löhken, A. Mewis, Z. Anorg. Allg. Chem. 627 (2001) 1213.

[14] B.Y. Kotur, R.I. Andrusyak, Inorg. Mater. 27 (1991) 1207.

[15] H. Noël, M. Potel, D. Kaczorowski, J. Alloys Compd. 302 (2000) L1.

[16] P. Hohenberg, W. Kohn, Phys. Rev. 136 (1964) B864.

[17] W. Kohn, L. J. Sham, Phys. Rev. 140 (1965) A1133.

[18] G. Kresse, J. Furthmüller, Phys. Rev. B 54 (1996) 11169.

[19] G. Kresse, J. Joubert, Phys. Rev. B 59 (1999) 1758.

[20] P. E. Blöchl, Phys. Rev. B 50 (1994) 17953.

[21] J. Perdew, K. Burke, M. Ernzerhof, Phys. Rev. Lett. 77 (1996) 3865.

[22] D. M. Ceperley, B. J. Alder, Phys. Rev. Lett. 45 (1980) 566.

[23] W.H. Press, B.P. Flannery, S.A. Teukolsky, W.T. Vetterling, Numerical Recipes, Cambridge University Press, New York (1986). 
[24] M. Methfessel, A. T. Paxton, Phys. Rev. B 40 (1989) 3616.

[25] A. R. Williams, J. Kübler, C. D. Gelatt, Phys. Rev. B 19 (1979) 6094.

[26] V. Eyert, The Augmented Spherical Wave Method - A Comprehensive Treatment, Lecture Notes in Physics, Springer, Heidelberg (2007).

[27] R. Hoffmann, Angew. Chem. Int. Ed. Engl. 26 (1987) 846.

[28] J. Emsley, The Elements, Oxford University Press, Oxford (U.K.), 1999.

[29] M. Francois, G. Venturini, J.F. Marêché, B. Malaman, B. Roques, J. LessCommon Met. 113 (1985) 231.

[30] R. Bader, Chem. Rev. 91 (1991) 893.

[31] S. F. Matar, A. Mavromaras, J. Solid State Chem. 149 (2000) 449-454.

[32] P. Mohn, Magnetism in the solid state - An introduction, Springer Series, in: Solid-State Sciences. M. Cardona, P. Fulde, K. von Klitzing, R. Merlin, H.J. Queisser, H. Störmer (Eds.). Springer, Heidelberg (2003). 


\section{Table 1}

$A_{4} T_{7} X_{6}: \operatorname{Im} \overline{3} m ; A\left(\begin{array}{lll}1 / 4 & 1 / 4 & 1 / 4\end{array}\right), T 1\left(\begin{array}{lll}0 & 0 & 0\end{array}\right), T 2\left(\begin{array}{lll}1 / 4 & 0 & 1 / 2\end{array}\right), X\left(\begin{array}{lll}x & 0 & 0\end{array}\right)$. PAW-GGA calculations. $\chi$ is the Pauling electronegativity.

a)

\begin{tabular}{|l|l|l|l|l|l|}
\hline$A_{4} T_{7} X_{6}$ & $\mathrm{a}_{\text {exp. }}(\AA),\left(\mathrm{a}_{\text {calc. }}(\AA)\right)$ & $x_{\text {exp. }}\left(x_{\text {calc. }}\right)$ & $\mathrm{Q}(A)\{\chi\}$ & $\mathrm{Q}(T 1 / T 2)\{\chi\}$ & $\mathrm{Q}(X)\{\chi\}$ \\
\hline $\mathrm{Mg}_{4} \mathrm{Rh}_{7} \mathrm{P}_{6}$ & $7.84(7.88)$ & $0.318(0.32)$ & $+2.0\{1.31\}$ & $-0.04 /-0.64\{2.28\}$ & $-0.68\{2.2\}$ \\
\hline $\mathrm{Sc}_{4} \mathrm{Co}_{7} \mathrm{Ge}_{6}$ & $7.85(7.83)$ & $0.290(0.30)$ & $+2.08\{1.36\}$ & $-0.71 /-0.72\{1.88\}$ & $-0.55\{2.0\}$ \\
\hline $\mathrm{Ti}_{4} \mathrm{Co}_{7} \mathrm{Ge}_{6}$ & $7.67(7.66)$ & $0.290(0.30)$ & $+1.89\{1.54\}$ & $-0.8 /-0.69\{1.88\}$ & $-0.44\{2.0\}$ \\
\hline
\end{tabular}

b)

\begin{tabular}{|l|l|l|l|l|l|}
\hline$A_{4} T_{7} X_{6}$ & $a_{\text {exp. }}(\AA),\left(a_{\text {calc. }}(\AA)\right)$ & $x_{\text {exp. }}\left(x_{\text {calc. }}\right)$ & $\mathrm{Q}(A)\{\chi\}$ & $\mathrm{Q}(T 1 / T 2)\{\chi\}$ & $\mathrm{Q}(X)\{\chi\}$ \\
\hline $\mathrm{U}_{4} \mathrm{Re}_{7} \mathrm{Si}_{6}$ & $8.224(8.253)$ & $0.290(0.30)$ & $+1.23\{1.38\}$ & $-0.42 /-0.64\{1.9\}$ & $-0.28\{1.9\}$ \\
\hline $\mathrm{U}_{4} \mathrm{Ru}_{7} \mathrm{Ge}_{6}$ & $8.293(8.304)$ & $0.290(0.31)$ & $+1.30\{1.38\}$ & $-0.42 /-0.50\{2.2\}$ & $-0.28\{2.0\}$ \\
\hline $\mathrm{U}_{4} \mathrm{Ru}_{7} \mathrm{As}_{6}$ & $8.305(8.316)$ & $0.318(0.32)$ & $+1.37\{1.38\}$ & $-0.26 /-0.33\{2.2\}$ & $-0.54\{2.18\}$ \\
\hline
\end{tabular}




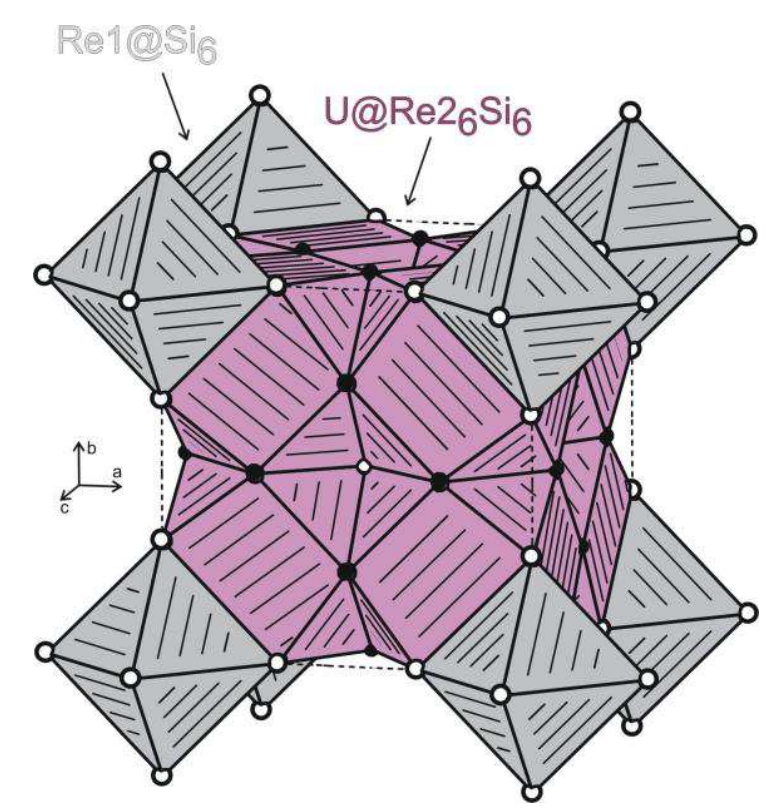

Fig. 1. (color online) The crystal structure of $U_{4} \operatorname{Re}_{7} \mathrm{Si}_{6}$. Uranium (hidden in the cuboctahedra), rhenium and silicon atoms are drawn as medium grey, black filled and open circles, respectively. The condensation pattern of $\mathrm{Re} 1 @ \mathrm{Si}_{6}$ octahedra and $\mathrm{U} @ \operatorname{Re} 2{ }_{6} \mathrm{Si}_{6}$ cuboctahedra is emphasized.

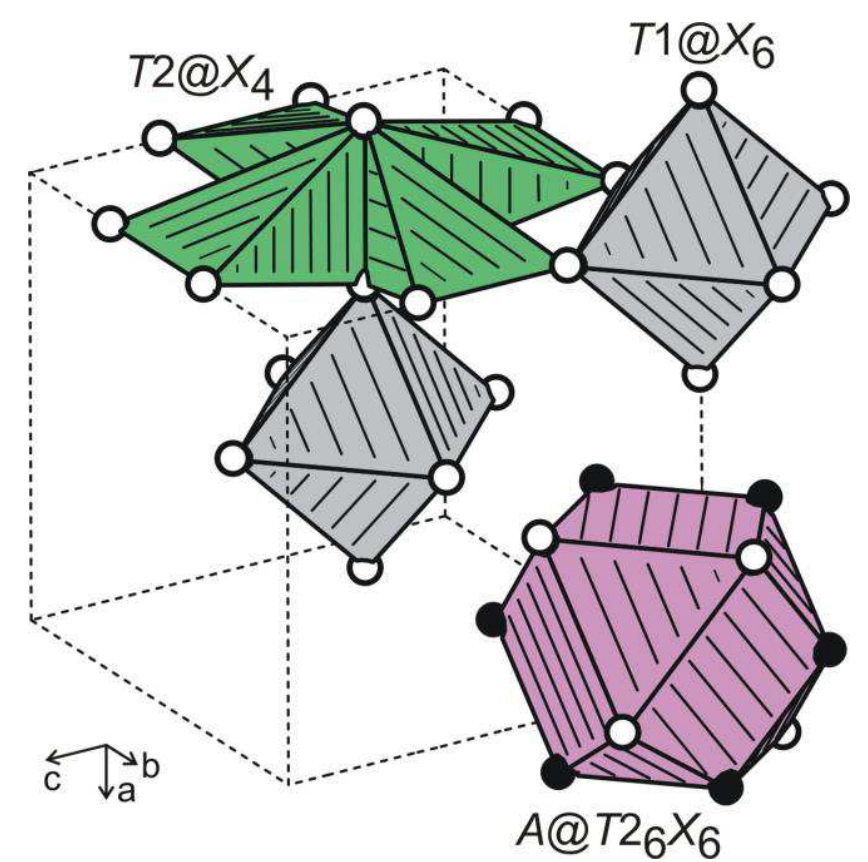

Fig. 2. (color online) Cutout of an $A_{4} T_{7} X_{6}$ unit cell. The polyhedra around the $A, T 1$, and $T 2$ atoms are emphasized. 

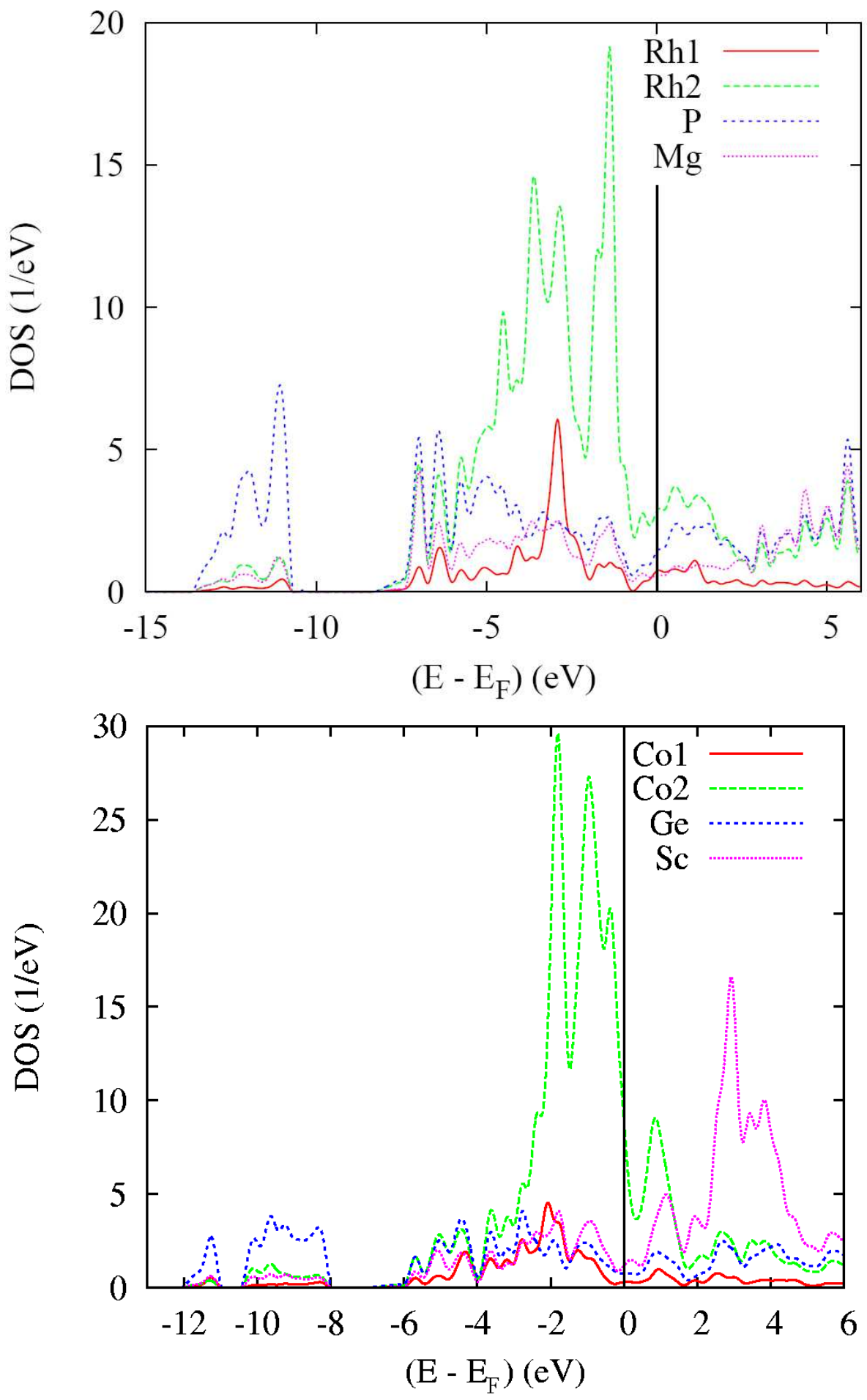


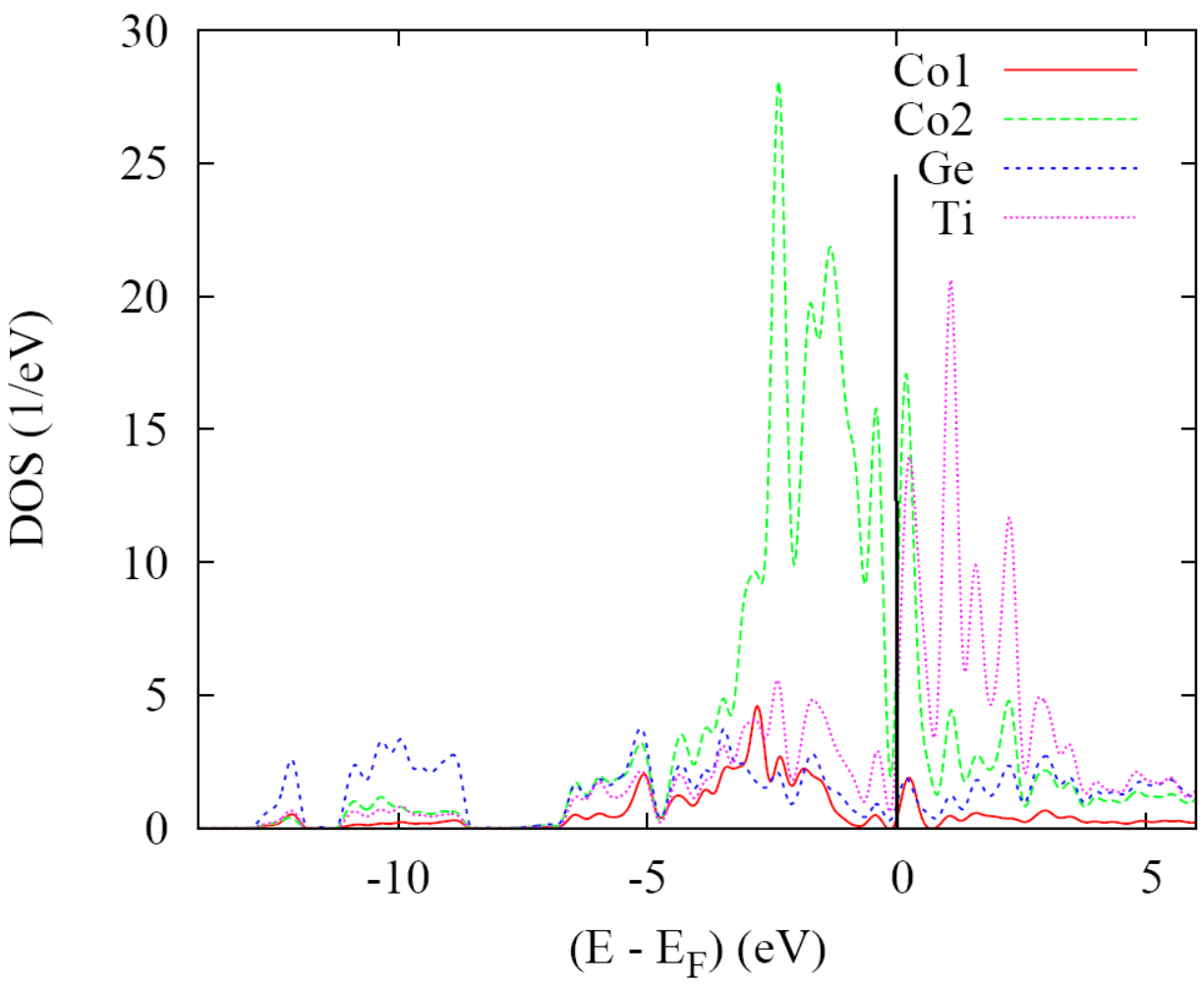

Fig. 3. (color online) Non magnetic spin degenerate NSP site projected DOS of $\mathrm{Mg}_{4} \mathrm{Rh}_{7} \mathrm{P}_{6}$ (top), $\mathrm{Sc}_{4} \mathrm{Co}_{7} \mathrm{Ge}_{6}$ (middle) and $\mathrm{Ti}_{4} \mathrm{Co}_{7} \mathrm{Ge}_{6}$ (bottom). 

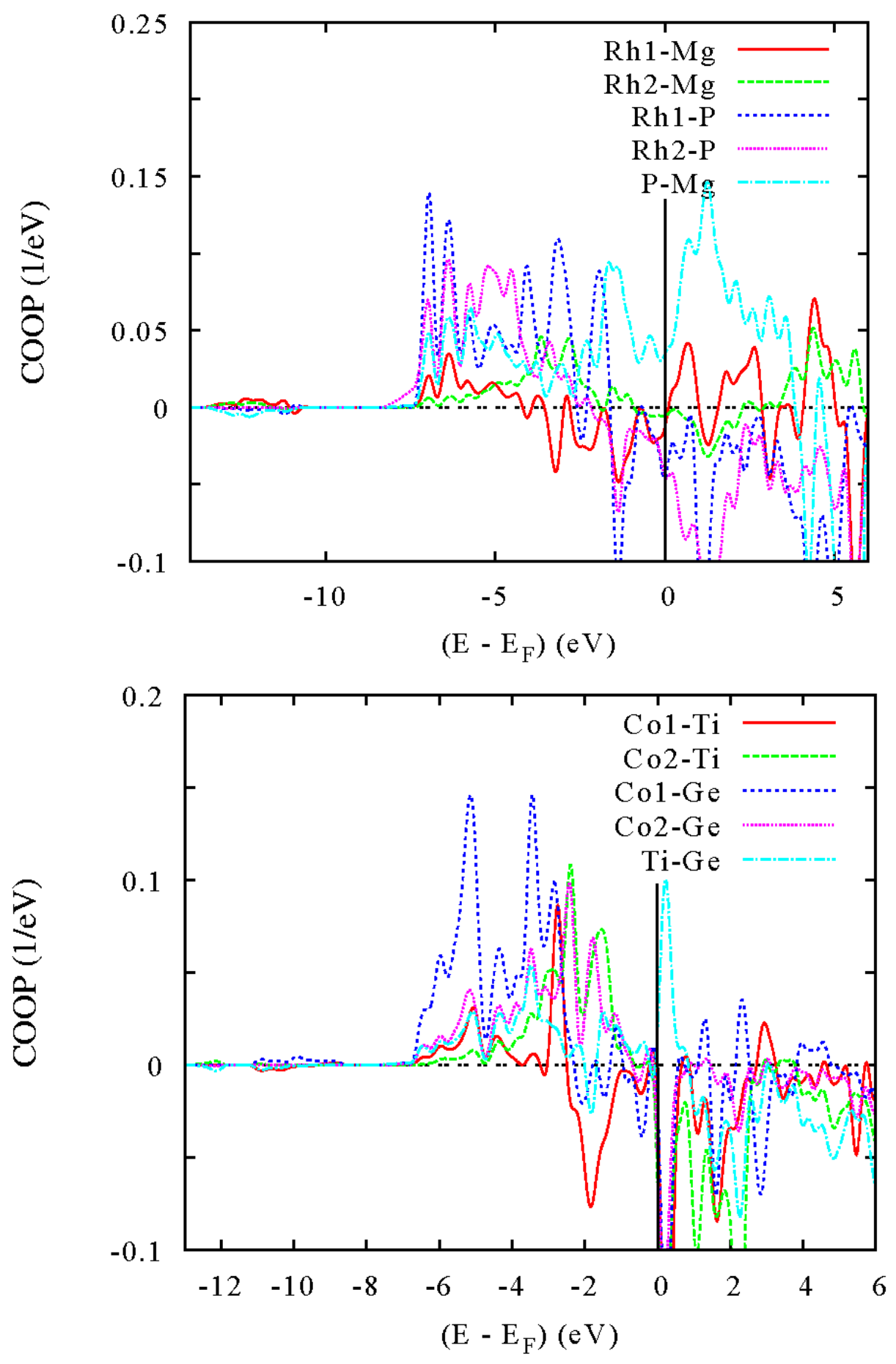


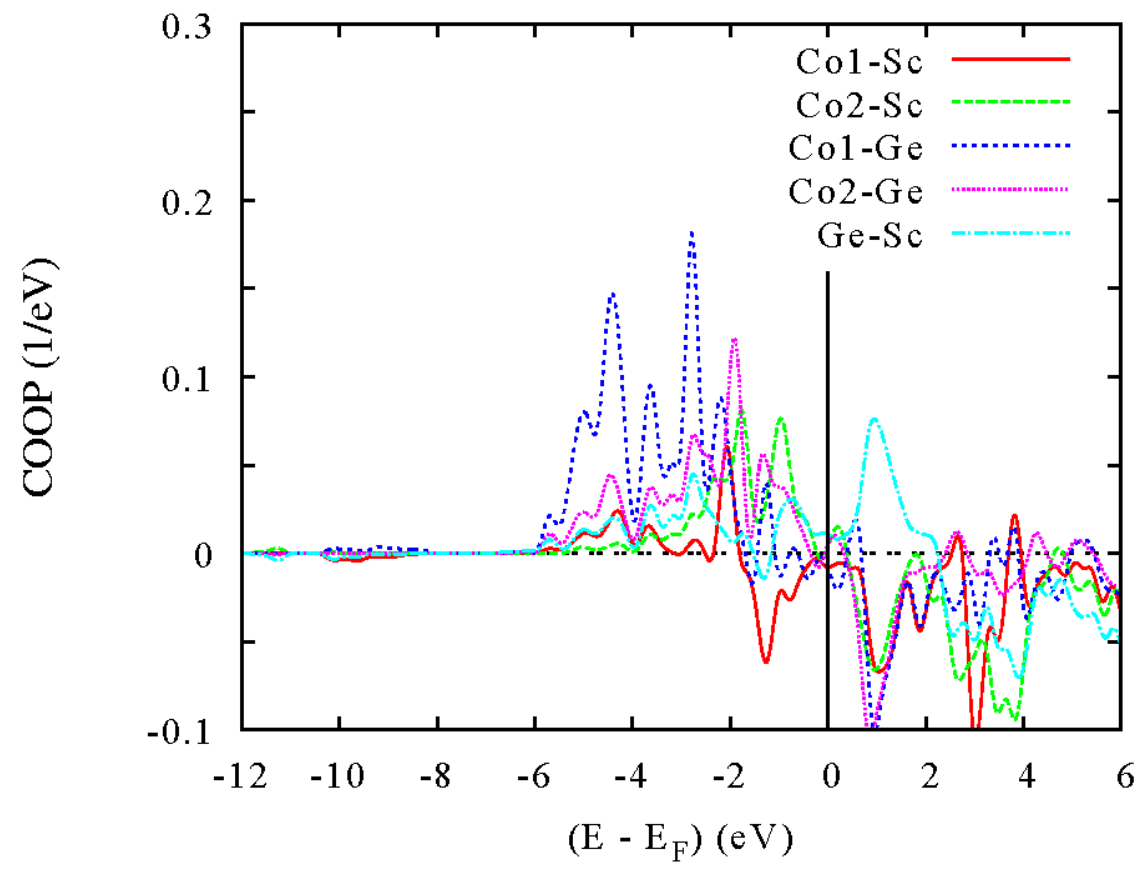

Fig. 4. (color online) $\mathrm{COOP}$ for atom-to-atom interactions in of $\mathrm{Mg}_{4} \mathrm{Rh}_{7} \mathrm{P}_{6}$ (top), $\mathrm{Sc}_{4} \mathrm{Co}_{7} \mathrm{Ge}_{6}$ (middle) and $\mathrm{Ti}_{4} \mathrm{Co}_{7} \mathrm{Ge}_{6}$ (bottom). 

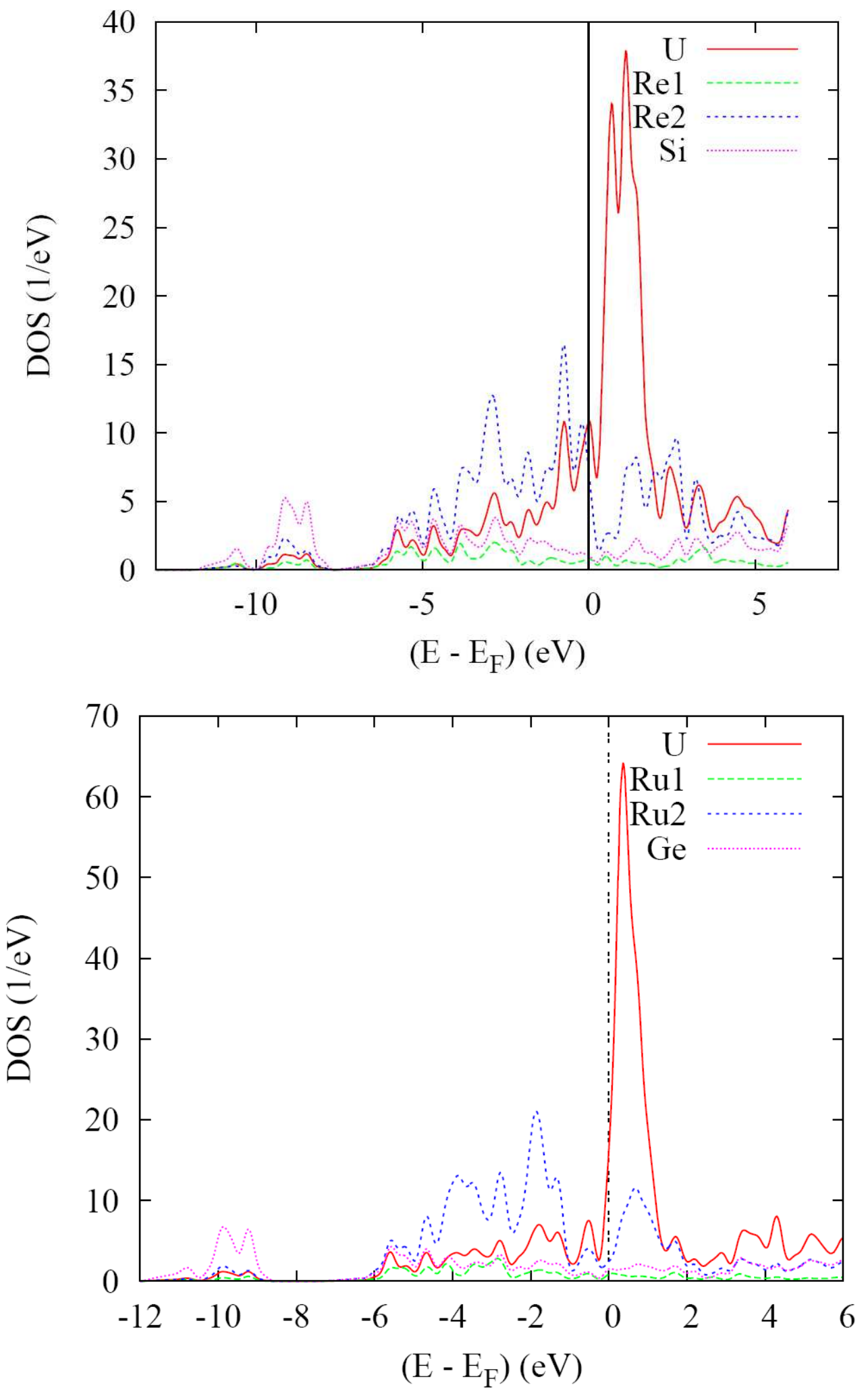


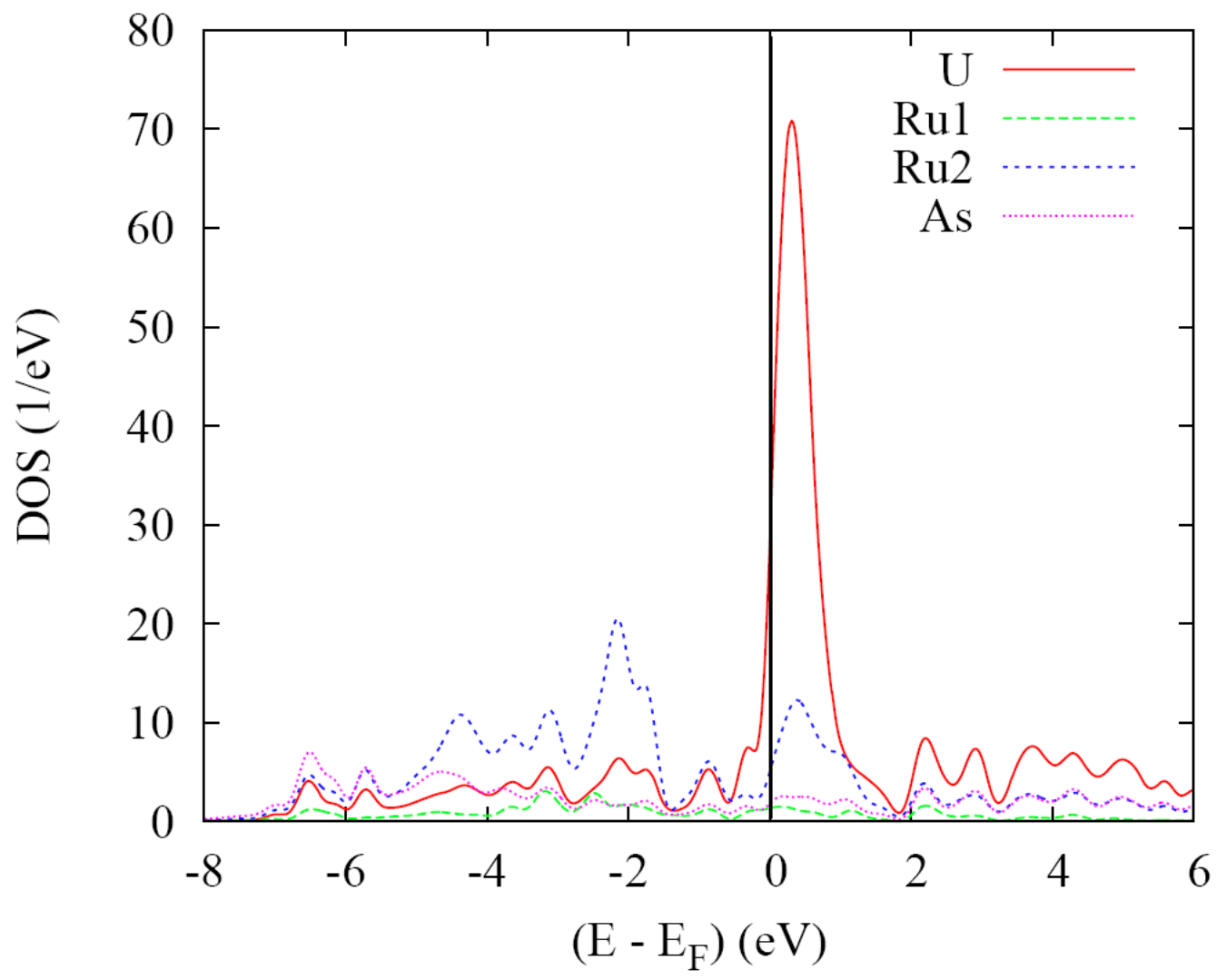

Fig. 5. (color online) Non-magnetic NSP PDOS for $U_{4} \operatorname{Re}_{7} \mathrm{Si}_{6}$ (top), $\mathrm{U}_{4} \mathrm{Ru}_{7} \mathrm{Ge}_{6}$ (middle) and $\mathrm{U}_{4} \mathrm{Ru}_{7} \mathrm{As}_{6}$ (bottom). 

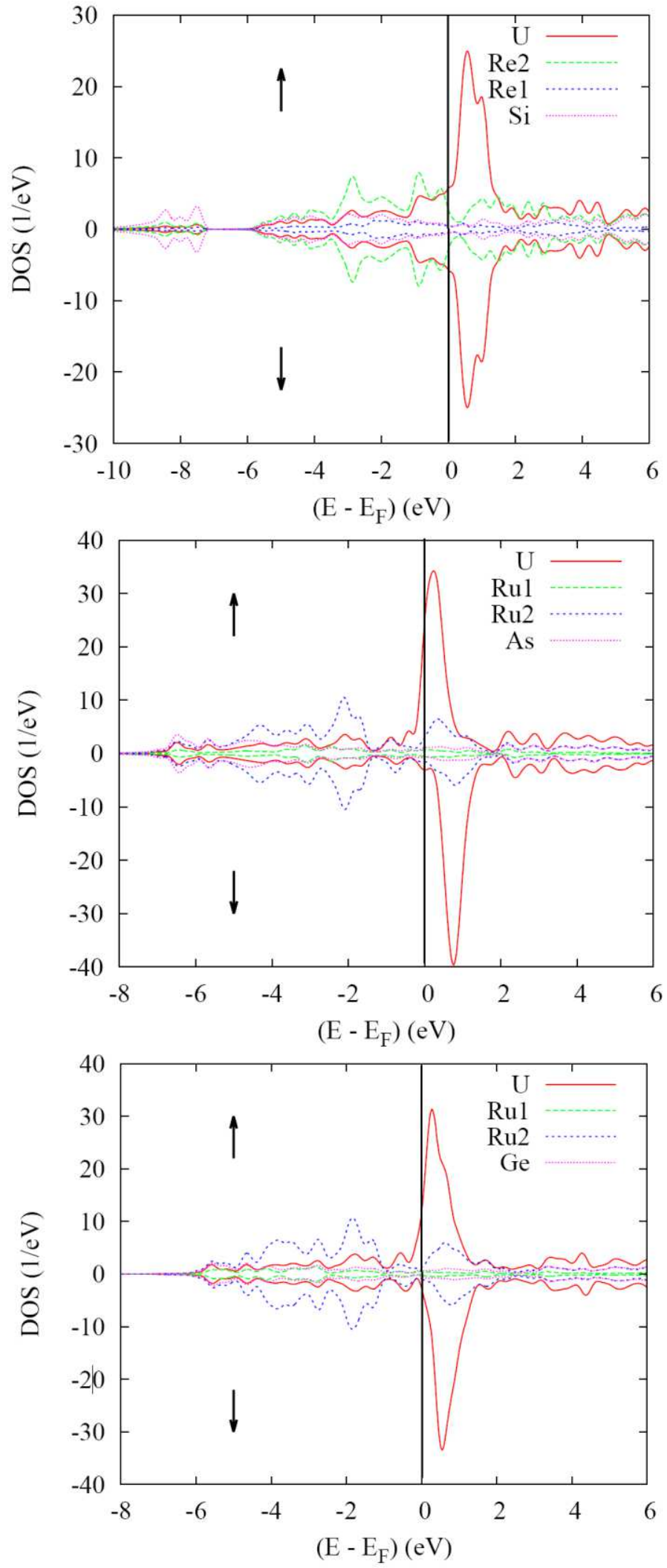

Fig. 6. (color online) Spin polarized SP site and spin projected DOS for $\mathrm{U}_{4} \mathrm{Re}_{7} \mathrm{Si}_{6}$ (top), $\mathrm{U}_{4} \mathrm{Ru}_{7} \mathrm{Ge}_{6}$ (middle) and $\mathrm{U}_{4} \mathrm{Ru}_{7} \mathrm{As}_{6}$ : (bottom). 